\title{
INDONESIA BARU DI TENGAH PERTARUNGAN ANTARA MOSAIK BUDAYA YANG ELOK DAN KAYA DENGAN ANCAMAN KESERAKAHAN*
}

\author{
Oleh: Ahmad Syafii Maarif*
}

\section{Abstract}

This paper is a sorrow reflection of writer toward the paradox reality of Indonesian people, which in one hand known as the religious society, granted by God the beautiful and wealth nature, but in other hand it was treated by greedy and corrupted birocracy. The big question of writer, why it happened, the religious Indonesian people couldn't look after the motherland of Indonesia, founded by the sacrifice of founding fathers of this nation? Actually, the writer argues that the religious quality ought to seem on moral quality in relation with among people, the universe, and God. It does not belong to this nation yet. Therefore, according to the writer, the struggle for that must always be done in order to the heart and the common sense become the safer of this nation.

هذا البحت نتيحة تأمل الكاتب بحاة الواقع المتتاقض في اليحتمع الإندونيسي الملتز مين

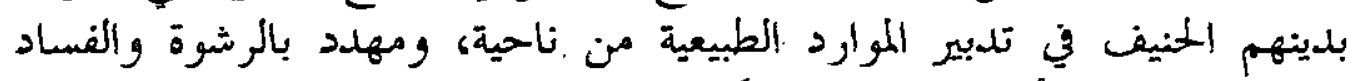

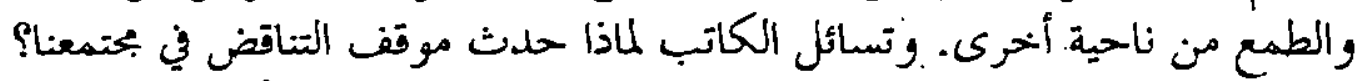

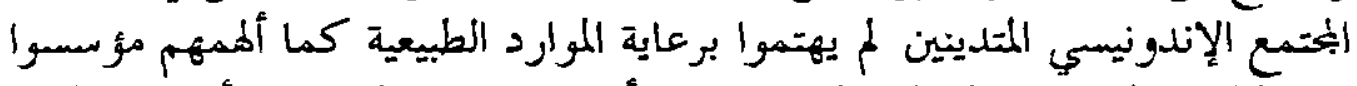

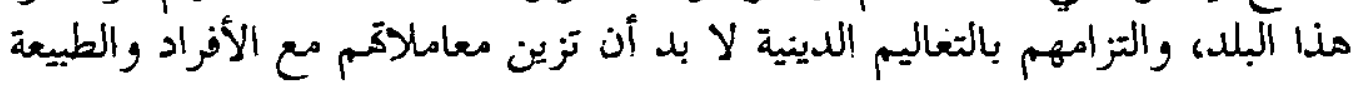

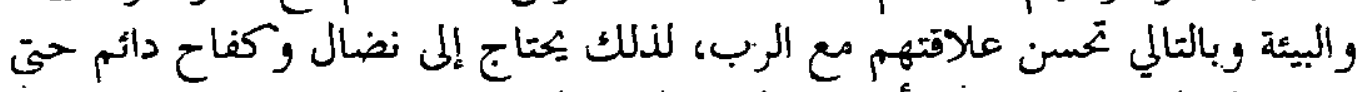

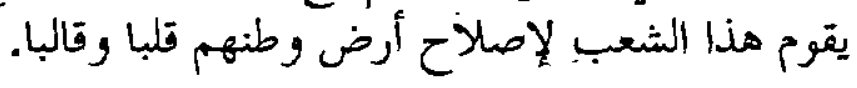

Kata kunci: ancaman keserakahan, esensi agama, Indonesia, mosaik budaja

'Disampaikan pada acara Penerimaan Anugerah Hamengku Buwono IX pada tanggal 20 Desember 2004 di Universitas Gadjah Mada Yogyakarta. Ahmad Syafii Maarif yang dikenal sebagai ketua PP Muhammadiyah beserta Saparinah Sadli lolos seleksi dari 57 cendekiawan terpilih yang diajukan dari seluruh indonesia.

“Guru Besar di Universitas Negeri Yogyakarta. 


\section{A. Pendahuluan}

Secara harfiah, mosaik berasal dari Bahasa Yunani Kuno mouseios, berarti sekeping karya seni dekoratif sebagai hasil perpaduan dari pecahan-pecahan batu atau gelas yang penuh warna warni, sehingga membentuk sebuah pola atau gambar. ${ }^{1}$ Indonesia tercinta yang terdiri dari 17.565 pulau besar dan kecil sebenarnya adalah sebuah mosaik fisik dan budaya yang teramat elok dan menawan dengan kekayaan alam yang masih potensial dan memberi harapan untuk kemakmuran dan kesejahteraan rakyat banyak, jika saja dikelola secara baik dan jujur. Hutan rimba sekalipun telah banyak digunduli dan dipetak-petak secara serakah, dan di beberapa daerah kondisinya sudah teramat parah, Indonesia masih punya hutan lindung yang sebagian merupakan paru-paru dunia yang dibanggakan oleh seluruh penduduk bumi. Kekayaan laut bangsa masih memuat harapan untuk kepentingan kemakmuran bersama, jika pencurian ikan serta pasir dihentikan sekarang juga dan untuk selama-lamanya. Memang diperlukan kepemimpinan nasional yang berani mengambil keputusan, tetapi bijak dan adil untuk memperbaiki borok-borok bangsa yang sudah parah ini. Ibarat kanker, kondisinya sudah berada pada tahap ketiga.

Korupsi sebagai salah satu bentuk keserakahan meskipun masih menggurita, toh di antara anak bangsa yang bersih, jumlahnya jauh lebih besar. Petani-petani, nelayannelayan, dan buruh-buruh kecil sekalipun belum merasakan benar apa makna merdeka bagi perbaikan nasibnya, mereka tidak akan memberontak, karena mereka memang tidak punya daya dan kesempatan untuk itu. Mereka inilah dalam jumlah puluhan juta yang belum merasakan rahmat kemerdekaan, sekalipun nenek moyang mereka tidak mustahil telah turut membantu para pejuang semasa pergerakan nasional untuk melihat negeri ini merdeka pada suatu hari, dan di masa revolusi telah menyumbang untuk mempertahankan kedaulatan bangsa dan negara ini yang masih terancam.

Namun ada pula sosok lain yang nenek moyangnya belum tentu turut berjuang mengawal revolusi, sementara keadaan lainnya telah cukup gemuk dan tambun oleh berbagai fasilitas yang didapatnya, berkat kemahirannya dalam memainkan seni kolusi dengan para pejabat dan aparat. Mereka ini termasuk jenis "Iondo ireng" dengan mental kumuh penuh daki. Oleh sebab itu dalam menghadapi berbagai kasus kriminal, orang sering sukar membedakan antara oknum pejabat dan penjahat. Ini adalah "mosaik" lain yang tidak elok dipandang mata dan tidak boleh dibiarkan untuk terus mengacau republik ini dimasa depan. Mengapa bangsa yang dikatakan relijius ini tidak pandai menjaga

${ }^{1}$ Lihat David B. Guralnik et. al. (ed.), 1970, Webster's New World Dictionary of The American Language, New York: The World Publising Company, hal. 488; Jonthan Metcalf et. al. (ed.), 1998, Illustrated Oxford Dictionary, New York-London: Oxford University Press, hal. 530. 
amanah kemerdekaan yang telah begitu banyak meminta korban itu? Apakah semangat multikultural dapat dijadikan modal untuk menjaga mosaik budaya Indonesia yang sangat kaya itu di masa datang yang tidak terlalu jauh? Bagaimana memerangi keserakahan yang dapat meluluhlantahkan semua yang sudah dibangun selama ini dan hampir saja meruntuhkan keutuhan bangsa ini? Jawaban terhadap pertanyaan-pertanyaan inilah yang ingin disampaikan dalam orasi penerimaan Anugerah Hamengkubuwono IX dalam rangka dies Universitas Gadjah Mada yang membahagiakan kami sekeluarga.

\section{B. Relijiusitas, Kebebasan Berfikir, dan Langkanya Negarawan}

Secara formal dan berdasarkan sensus penduduk tahun 2000 , hampir $100 \%$ rakyat Indonesia mengaku menganut agama tertentu: Islam $(88,22 \%)$, Kristen/Katolik $(8,92 \%)$ Hindu (1,81\%), Budha $(0,84 \%)$, dan Kong Hu-Chu (sekitar $0,82 \%$ tahun 1971), lain-lain $(0,20 \%)^{2}$ Prosentase rakyat yang tidak jelas agamanya ternyata kecil sekali, yaitu hanya $0,20 \%$. Persoalannya bukan terletak pada kualitas mental mereka dalam menjalankan agamanya masing-masing dalam upaya menjaga dan mengawal moral bangsa sehingga tidak merosot tajam seperti sekarang ini. Bagi penulis, kualitas relijiusitas seseorang harus terlihat pada kualitas moralnya dalam berhubungan dengan sesama, alam semesta, dan dengan Tuhan. Kualitas hubungan menaik dengan Tuhan (Langit) harus tampak pula pada dimensi hubungan mendatar dengan sesama makhluk dan dengan lingkungan alam. Harmonisasi hubungan tiga dimensional ini merupakan pra-syarat untuk tegaknya sebuah bangunan peradaban yang boleh jadi akan bertahan lama, termasuk diharapkan yang telah dan akan berkembang di nusantara ini.

Dalam perspektif di atas, orang tidak boleh misalnya mengklaim bahwa dia telah punya hubungan baik dengan Tuhan, jika pergaulannya dengan sesama umat di muka bumi berada dalam kondisi kumuh dan penuh curiga. Inilah barangkali yang dibidik oleh al-Qur'an: "Ditimpakan kehinaan atas diri mereka di mana pun mereka berada, kecuali (mereka berpegang) dengan tali Allah dan tali manusia." (Q.S. III: 112). Agama yang fungsional dengan demikian adalah yang mampu menjaga hubungan erat dengan Langit serta dirasakan pula sentuhan positifnya pada dimensi mendatar dalam format persaudaraan yang tulus antar pemeluk beriman, bahkan dengan yang tidak beriman. $D i$ Juar itu, agama tidak lebih dari serimoni dan upacara kosong tanpa makna, sekalipun dalam penyelenggaraan lahiriah terkesan gemerlapan. Agama yang benar-benar fungsional adalah agama yang mampu mengawal perilaku moral pemeluknya.

${ }^{2}$ Lihat Leo Suryadinata, Evi Nurvidya Arifin, Aris Ananda, 2003, Indonesia's Population: Ethnicity and Religion in a Changing Political Landscape, Singapore: Institute of Southeast Asian Studies, hal. 104. 
Di atas planet bumi yang semakin sesak ini dengan keanekaan bahasa dan tutur kata sebagai wujud dari kekayaan multikultural, tidak ada opsi lain, kecuali mengembangkan budaya lapang dada dan santun, dengan tidak memandang latar belakang agama, etnisitas, dan ideologi politik, dengan syarat semuanya itu dilakukan secara jujur dan tulus. Rasisme yang belum menghilang seluruhnya dalam dunia modern haruslah dipandang sebagai daki peradaban yang tidak boleh dibiarkan berkembang dengan alasan apapun. Agama yang disalah gunakan untuk membela rasisme merupakan sesuatu yang destruktif dan politik semacam itu perlu secepatnya dimasukkan ke dalam museum sejarah.

Selanjutnya bila kondisi moral bangsa sekarang ini diteropong dengan cermat, maka tidaklah salah kalau dapat disimpulkan bahwa agama belum berfungsi secara benar dan efektif dalam kehidupan kolektif bangsa secara keseluruhan. Terlalu banyak penyimpangan dan bahkan kejahatan moral yang dilakukan, tidak jarang atas nama Tuhan. Ini tidak lain dari perbuatan orang yang membajak Tuhan untuk kepentingankepentingan rendah sesaat tanpa rasa berdosa dan menyesal. Pemandangan yang tidak elok ini tidak boleh diperagakan terus, sebab pasti akan memuakkan orang yang berpikir jernih dan dalam, apa pun agama dan sukunya. Semuanya ini berlaku di wilayah politik, ekonomi, dan sosial dalam tenggang waktu yang sudah agak lama. Indonesia adalah sebuah bangsa yang mengaku beragama, tetapi setiap hari dan setiap malam nilai-nilai luhur agama itu diinjak dan diperkosa dengan dipayungi oleh berbagai pembenaran teologis dan kutipan-kutipan sakral. Keserakahan di kalangan segelintir orang memang telah merusak bangunan bangsa ini selama beberapa dasa warsa, dan sekarang harus dihentikan melalui penegakan hukum dan sikap tegas dari pemerintah.

Sama halnya dengàn mereka yang sering berlindung di balik Pancasila, sematamata untuk menutup syahwat kekuasaan sebagai agenda tersembunyinya. Pada periode Ialu, berbagai penataran tentang Pancasila telah dilakukan dengan biaya ratusan milyar. Apa yang terjadi adalah semakin sering ditatar, semakin rusak saja moral bangsa ini. Bukan karena Pancasila, tetapi semata-mata karena pengkhianatan masyarakat terhadap nilai-nilainya yang luhur. Perbuatan mereka mencabuli apa yang mereka katakan. Terjadi keretakan antara kata dan laku. Wahai orang-orang yang beriman: "Mengapa kamu berkata tentang sesuatu yang tidak kamu lakukan? Besar kemurkaan di sisi Allah lantaran kamu berkata apa yang tidak kamu lakukan," teguran keras al-Qur'an dalam sebuah surat Madaniah. (Q LXI:2-3). Teguran ini sudah disampaikan sejak puluhan abad yang lalu, justru kepada pemeluk beriman. Oleh sebab itu iman bukan digembor-gemborkan dan menakut-nakuti pihak lain, tetapi untuk dibuktikan dalam perbuatan baik yang dirasakan semua orang. Perbuatan baik inilah yang menjadi indikator litama, apakah seorang beriman atau tidak, yaitu beriman secara autentik, bukan iman yang dibungkus dalam jubah kepalsuan, iman basa-basi. Agama yang fungsional adalah agama yang 
mampu mengawinkan antara kekuatan spiritual dengan perbuatan baik dan mulia dalam kehidupan bersama. Dalam ungkapan lain, agama yang mampu mengawal arus peradaban, bukan yang terseret oleh kekuatän-kekuatan sosial yang destruktif.

Sekarang memasuki kajian tentang wilayah hubungan agama dan kebebasan berpikir pada skala yang lebih mondial untuk meluaskan wawasan intelektual sebagai bangsa merdeka. Salah satu buah dari gerakan Renaisans di Eropa abad ke-16 adalah munculnya gelombang modernitas yang tak terbendung sampai hari ini. Salah satu buahnya adalah bahwa manusia modern didorong untuk berpikir sebebas-bebasnya, sehingga doktrin-doktrin agama dan keimanan kepada Tuhan dipandang sebagai sesuatu yangmembelenggu dan ketinggalan zaman, dan karena itu harus disingkirkan. Segala apa yang menghambat kemajuan saintifik adalah musuh, menurut cara berpikir modern itu. Sudah sejak abad ke-19, F. Nietzsche bukan saja mengumumkan Tuhan telah mati, tetapi "Tuhan ini," tulisnya, "adalah bahaya terbesar bagimu." Deklarasi "Tuhan telah mati" (God is dead) Nietzsche telah menimbulkan heboh yang luar biasa di kalangan penganut agama formal, tetapi jika ditengok masalahnya dengan tilikan yang lebih jernih dan seksama, mungkin akan sedikit terlihat simpati kepada filosof kontroversial Jerman ini. Bukankah agama pada abad ke-19 itu dan juga pada abad-abad sebelumnya sudah tidak lagi berfungsi secara efektif sebagai pengawal peradaban dan nilai-nilai tinggi? Tokoh-tokoh agama bahkan menentang temuan-temuan ilmu pengetahuan berdasarkan data empirik yang tak terbantahkan. Jadi apa yang dikemukakan Nietzsche sebenarnya tidak lebih dari tafsirannya tentang krisis peradaban sekuler antroposentris akibat kegagalan agama dan nilai-nilai spiritual dalam menyediakan jawaban terhadap pemikiran serta temuan ilmiah yang sedang berkembang. Hanya kelemahannya, filosuf ini menggunakan ungkapan yang serba ekstrim sehingga memancing reaksi yang sangat hebat. Apa yang sedang disaksikan sesungguhnya adalah melajunya kereta zaman yang sudah tak mungkin dihentikan lagi, maka Nietzsche "lalu mendorongnya sampai ke batas", ${ }^{4}$ tulis Hollingdale, penerjemah Zarathustra dari bahasa Jerman ke dalam bahasa Inggris.

Nietzsche pada akhirnya memang menjadi nihilis, sementara kerinduan untuk menemukan Tuhan pada waktu itu telah menemui jalan buntu, dan dia sendiri kemudian menjadi gila, 11 tahun sebelum meninggal pada 25 Agustus 1900 dalam usia 56 tahun. Barangkali tidak ada penulis mana pun yang mendefinisikan nihilisme setajam Nietzsche, yaitu situasi di mana "manusia berguling dari pusat menuju $X$ ", sehingga seperti ungkapan Heidegger, pada ujungnya 'there is nothing left' of Being as such (tidak ada lagi yang

${ }^{3}$ F. Niezsche, 1976, Thus Spoke Zarathustra, terj. R.J. Hollingdale, New York: Penguin Books, hal. 297.

"Ibid., lihat "Pengantar", hal. 13. 
tersisa dari Yang Ada itu). ${ }^{5}$ artinya Tuhan telah menghilang dalam pergaulan umat manusia, atau karena "telah mati", kata Nietzsche. Akibatnya memang sangat dahsyat, yaitu berlakunya proses devaluasi (kemerosotan) dari nilai-nilai tertinggi ${ }^{6}$ dalam kehidupan modern. Dalam kalimat Charles Taylor: "People no longer have a sense of a higher purpose, of something worth dying for." Teknologi hanyalah mempercepat proses kemerosotan ini, karena kawalan spiritual telah demikian lemah.

Pemikiran bebas ini adalah bagian dari modernitas kultural yang implikasiimplikasinya menurut Habermas meliputi: (1) individualisme, (2) kebebasan dan kemampuan untuk menundukkan tradisi kepada penalaran kritikal, (3) otonomi tindakan individu, dan (4) filsafat tentang manusia yang menghasilkan pandangan dunia yang berpusat pada manusia (a man-centered view of the world) ${ }^{8}$ Implikasi keempat inilah terutama yang memberi peluang kepada manusia sebebas-bebasnya dan seluas-luasnya untuk mengaktualisasikan seluruh potensi diri tanpa merujuk kepada sesuatu yang transendental atau kepada "an ultimate spiritual reality which gives the universe its meanig and value," dalam ungkapan A.J. Toynbee. ${ }^{9}$ Pernyataan Nietzsche tentang kematian Tuhan hendaklah dibaca melalui kacamata modernitas kultural ini. Pada permulaan abad ke-21 ini, karya-karya Nietzsche tampaknya semakin digemari orang, terutama di Barat, karena beberapa ramalannya memang terbukti, di samping ungkapanungkapan sastranya yang provokatif.

Direkamkan laporan tentang Nietzsche ini, semata-mata untuk menunjukkan bahwa agama bila telah kehilangan fungsinya sebagai pengawal moral dan gerak peradaban, maka ia akan dilupakan orang, setidak-tidaknya diketepikan. Atau jika secara formal masih terlihat, yang berlaku tidak lain selain upacara-upacara ritual dan seremonial tanpa makna, sementara subtansinya sebagai acuan moral telah ditelan arus komersialisasi yang ganas dan tidak mengenal iba. Indonesia memang belum melahirkan Nietzsche sebagai pengamat sangat kritikal terhadap fenomena Tuhan dan agama, tetapi bahwa

'Lihat Gianni Vattimo, 1991, The End of Modernity, terj. John R. Snyder, Baltimore: The Johns Hopkins University Press, hal. 19. Di Barat sekarang ini perhatian terhadap Nietzsche semakin meluas saja. Salah satu biografi filosofisnya ditulis oleh Rudiger Safranski, 2003, Nietzsche: $A$ Philosophical Biography, London: Granta Books, cukup penting untuk dibaca sebagai pengenalan awal terhadap filosuf ini. Sekarang hampir seluruh karyanya sudah tersedia dalam bahasa Inggris, dan beberapa dalam bahasa Indonesia.

'Ibid., hal. 20.

${ }^{7}$ Chatles Taylor, 1992, The Malaise of Modernity, Concord Ontario: Anansi, hal. 4.

${ }^{8}$ Lihat Bassam Tibi, 2002, The Challenge of Fundamentalism: Political Islam and The New World Disorder, Berke'ey: University of California Press, hal. 80, dikutip dari Jurgen Habermas, 1987, The Philosophical Discourse of Modernity, Cambridge Mass: MIT Press.

${ }^{9}$ Lihat A.J. Toynbee, 1973, Surviving The Future, New York-London: Oxford University Press, hal. 56. 
orang yang mengaku beragama telah menjual ayat-ayat Tuhan untuk kepentingan politik, posisi, dan sebagai mata pencaharian, juga tidak asing di Indonesia. Komersialisasi agama dengan kawalan jubah dan tasbih telah sangat memprihatinkan agamawan yang lurus dan sejati.

Di samping penjaja ayat, ada pula kelompok yang tampil radikal dan militan dengan memakai pakaian-pakaian khas, tetapi mental dan sikap dasarnya tidak lebih baik dari mental dan sikap preman. Fenomena semacam ini juga merisaukan pembacaan perkembangan masyarakat Indonesia kontemporer yang masih dilanda krisis. Di otak belakang kelompok radikal ini adalah kehausan terhadap kekuasaan. Jika kekuasaan itu dapat diraih, maka akan dibentuklah sebuah pemerintahan yang otoritarian, karena memang ke arah itulah mereka bergerak. Agama di tangan mereka tidak lebih dari pembenaran terhadap sistem kekuasaan yang memonopoli kebenaran itu. Oleh sebab itu, kelompok ini sangat anti demokrasi karena demokrasi memberi peluang kepada manusia untuk hidup damai dalam perbedaan, dalam iklim multikultural dan multiagama.

Namun, dalam sistem demokrasi, tentu saja kita tidak boleh menghukum kelompok-kelompok yang berwajah garang ini, selama mereka menghormati konstitusi, hukum, dan etika pergaulan. Tetapi penulis akan sangat keberatan terhadap tafsiran agama mereka yang monopolistik. Seakan-akan di luar paham mereka, tidak ada kebenaran. Tafsiran monopolistik ini jelas tidak sejalan dengan doktrin egalitarian yang diajarkan agama. Islam, misalnya, sangat tegas dalam membela prinsip persamaan ini. Kegagalan kaum fundamentalis menghadapi modernitas merupakan salah satu sebab mengapa sikap berani mati mereka sangat menonjol dan ditakuti. Sebenarnya, jika ditengok lebih dalam, sikap semacam ini adalah karena mereka telah kehilangan kepercayaan terhadap hidup, atau karena tidak punya gagasan apa pun yang dapat ditawarkan untuk memperbaiki kondisi peradaban manusia yang semakin bercorak nihilistik ini. Mereka lari dari tanggung jawab sejarah dengan melakukan berbagai tindakan teror dan kekerasan. Ini terjadi akbat pandangan yang serba medioker dan monolitik itu. Tetapi harap dicatat, bahwa yang melakukan teror bukan hanya mereka, tetapi ada pula bentuk teror yang lebih dahsyat, yaitu yang disponsori negara tertentu yang semakin membawa dunia menjadi kalang kabut dan lintang pukang dengan meninggalkan korban dalam jumlah jutaan manusia. Maka benarlah pendapat Johan Galtung dan Dietrich Fischer bahwa "untuk mengakhiri terorisme, akhiri terorisme negara". ${ }^{10}$ Apa yang berlaku di Palestina, Afganistan, dan Iraq adalah bagian skenario terorisme negara ini. Penulis terkenal Perancis, Emmanuel Todd menulis bahwa apa yang dikatakan ancaman global sebenarnya tidak ada. "Tidak ada ancaman global yang

${ }^{10}$ Lihat Johan Galtung dan Dietrich Fischer, 2002, "To End Terrorism, End State Terrorism" dalam Just Commentary, Vol. 2, No. 9, hal. 1. 
menuntut jawaban darurat oleh Amerika Serikat demi melindungi kemerdekaan. Hanya ada satu ancaman terhadap stabilitas global yang meliputi dunia sekarang-yaitu Amerika sendiri, yang pada masa lalu sebagai protector (pelindung) dan kini sebagai predator (pemangsa). ${ }^{11}$ Sungguh kritik Todd ini tepat dan tajam, sebab itulah yang disaksikan sekarang, dan Amerika tidak mau belajar dari berbagai petualangan politik imperialistiknya pada masa lampau, khususnya di Vietnam yang memaksa mereka angkat kaki dari sana.

Untuk membatasi gerak kelompok radikal destruktif dalam masyarakat, jalan yang terbuka adalah menegakkan sistem demokrasi secara sehat, di mana keadilan bagi masyarakat luas betul-betul dirasakan sebagai sesuatu yang hidup. Demokrasi yang hanya berhenti sebagai wacana, tetapi tidak dalam realitas, akan selalu memberi peluang kepada kelompok-kelompok yang tidak puas dalam masyarakat untuk menebarkan virus kebencian terhadap tatanan kekuasaaan yang sedang berlaku. Bahwa sebagian mereka terkooptasi oleh kekuasaan dalam berbagai periode juga bukan sesuatu yang asing dalam sejarah modern Indonesia. Di sinilah serba ironi fundamentalisme itu sering terlihat. Dalam satu situasi, kaum fundamentalis tampil dengan panji-panji idealisme yang memukau, tetapi pada situasi lain, jati dirinya sebagai kelompok yang haus kekuasaan tidak dapat disembunyikannya, karena rasion d'etre mereka memang untuk berkuasa, demi menggantikan sistem politik yang dinilainya serba sekuler dan tidak adil.

Tetapi yang sering luput dari perhatian publik adalah bahwa fundamentalisme dan sekularisme sesungguhnya sama-sama membuahkan dampak destruktif bagi sebuah keseimbangan sosial (social equilibrium) dalam masyarakat mana pun. Sistem Pancasila yang sudah disepakati, pada hakekatnya bertujuan untuk menciptakan sebuah tatanan masyarakat yang berimbang itu, dengan syarat sila-silanya dipahami sebagai sebuah kesatuan yang saling mengisi dan melengkapi. Dengan Pancasila, masyarakat telah memiliki modal filosofis sosial dan politik untuk membangun sebuah Indonesia modern yang berkeadilan dan bermartabat. Fungsi lain dari Pancasila adalah sebagai kekuatan pengikat unsur-unsur subkultur Indonesia yang sangat beragam lagi kaya itu.

Untuk itu, diperlukan lahirnya para negarawan yang secara kultural dan historis berakar kuat dalam darah daging bangsa ini. Maka dalam sistem demokrasi yang sehat, peluang untuk tampilnya para negarawan ini menjadi semakin besar sekalipun memerlukan waktu. Sistem politik yang otoritarian selama ini telah mengunci peluang untuk munculnya para negarawan Indonesia yang visioner itu. akibatnya dirasakan, yaitu semakin banyaknya politisi yang menjadikan politik lebih sebagai mata pencaharian, tetapi hanyalah sedikit sekali di antara mereka yang dapat diharapkan menjadi negarawan. Inilah di antara

"Emmanuel Todd, 2003, After The Empire: The Breakdown of The American Order, terj. C. Jon Delogu, London: Constable and Robinson, hal. 191. 
kelemahan bangsa yang cukup serius dalam bernegara setelah hampir 60 tahun Indonesia merdeka.

Oleh sebab itu, sebuah kondisi yang mantap bagi proses percepatan tampilnya para negarawan Indonesia modern ini perlu selalu diciptakan dan dipelihara, baik oleh negara maupun oleh masyarakat sendiri, dengan memberi peluang yang sama kepada semua warga negara yang berpotensi untuk itu. Dengan jalan ini diharapkan kelangkaan negarawan akan dapat diatasi dalam tempo yang tidak terlalu lama.' Adalah sebuah kenyataan sejarah bilamana rakyat Indonesia diberi peluang yang wajar untuk mengembangkan bakatnya sebagai calon negarawan, bibitnya cukup tersedia pada semua subkultur bangsa yang beragam itu. Oleh sebab itu demokrasi yang mulai menampakkan tanda-tanda baik ini tidak boleh dibunuh lagi dengan alasan apapun.

\section{Multikulturalisme, Mosaik Budaya Indonesia, dan Ancaman Keserakahan}

Secara historis, ciri utama multikulturalisme ialah adanya kenyataan tentang: 1 . Kebutuhan manusia terhadap pengakuan, 2. Perlunya legimitasi keragaman budaya atau pluralisme budaya. ${ }^{12}$ Dalam perspektif dua ciri ini, multikulturalisme dapat dijadikan benteng terhadap monokulturalisme sebagai bawaan dari gelombang globalisasi perpanjangan radius peradaban ekpansif barat modern, dalam arti positif atau negatif. Yang positif menyangkut dimensi ilmu dan teknologi yang bergerak dengan kencang, sedangkan yang negatif adalah serbuan nihilisme sebagaimana yang telah dibicarakan sebelumnya. Dengan adanya pengakuan dan legitimasi nilai-nilai budaya atau suatu masyarakat, maka kecenderungan yang serba mono (tunggal) dapat dihadapi dengan sikap percaya diri, karena apa yang dimiliki belum tentu sesuatu yang usang yang harus segera dibuang.

Tetapi filsafat multikultural jika tidak disikapi dengan hati-hati, dapat pula menyuburkan kebanggaan berlebihan terhadap budaya lokal atau nasional, tanpa sikap kritikaI. Oleh sebab itu mosaik subkultur Indonesia yang kaya dan beragam haruslah senantiasa membuka diri terhadap unsur-unsur luar yang positif, agar terhindar dari keterasingan lintas budaya, dalam proses memberi dan menerima. Dalam sebuah dunia yang semakin mengecil tanpa batas berkat teknologi informasi-komunikasi, maka hampir mustahil orang akan bebas dari pengaruh unsur kultur lain. Yang penting adalah agar milik bangsa ini jangan sampai tergusur, kecuali jika keadaannya memang sudah dalam proses membusuk, sehingga tidak mungkin lagi dipertahankan sebab sudah menjadi beban budaya itu sendiri.

${ }^{12}$ Lihat H.A.R. Tilaar, 2004, Multikulturalisme: Tantangan-tantangan Global Masa Depan dalam Transformasi Pendidikan Nasional, Jakarta: Grasindo, hal. 83. 
Dalam filsafat bhinneka tunggal ika yang telah menjadi doktrin pengikat bangsa Indonesia, khususnya sejak dicetuskannya Sumpah Pemuda 1928, multikulturalisme dapat memainkan peran positifnya agar mosaik sub-kultur bangsa yang baik dapat dipertahankan. Dalam peribahasa Minang yang terkait dengan masalah adat, dikenal ungkapan: "Tak lekang karena panas, tak lapuk karena hujan." tetapi ungkapan ini hanya mungkin berlaku dalam situasi isolatif, pada saat interaksi lintas budaya masih sulit karena belum disentuh teknologi modem. Begitu pula pribahasa yang sering terdengar, "Berani karena benar, takut karena salah." Dalam iklim demokrasi, peribahasa ini sudah ketinggalan, sebab yang dituntut orang adalah: "Berani itu benar, takut itu salah." Pers bebas adalah salah satu indikator dari ungkapan terakhir ini.

Kasus Munir misalnya telah dibicarakan secara bebas dan berani oleh pers, tinggal menanti tanggapan pemerintah terhadap tuntutan masyarakat yang ingin segera masalahnya terungkap tuntas dan gamblang. Membiarkan masalah peka ini tergantung di awan-awan dapat melemahkan legitimasi sosial dan moral pemerintah. Kabinet Indonesia Bersatu sebagai realisasi dari hasil pemilihan presiden/wakil presiden secara langsung oleh rakyat pada tanggal 20 September 2004 merupakan sebuah prestasi demokrasi yang sangat mengagumkan. Oleh sebab itu pemerintah wajib bersikap responsif terhadap keluhan dan tuntutan masyarakat, jika memang tuntutan itu punya substansi yang kuat. Kasus Munir yang telah mendapat perhatian luas jangan dibiarkan terlunta-lunta, sebab akibatnya akan sangat buruk bagi citra penegakan hukum di mata publik dunia. Seorang Munir yang tampaknya berpegang kepada diktum: "Berani itu benar, takut itu salah", adalah sosok anak bangsa yang semestinya tidak halaI diracun, sebab dari jumlah 220 juta rakyat Indonesia mencari tandingan keberanian Munir susah sekali. ${ }^{13}$

Akhirnya sampailah kepada bagian yang cukup genting dalam tulisan ini, yaitu tentang ancaman keserakahan yang dapat meluluhlantakkan mosaik budaya dan fisik nusantara yang telah lama dikenal dunia. Pembicaraan tentang korupsi tidak akan diperpanjang lagi dalam pidato ini, karena sudah terlalu membosankan. Tetapi perasaan tertampar muka Presiden Susilo Bambang Yudhoyono akibat sorotan mata 20 delegasi APEC di Santiago bulan lalu yang langsung mengarah kepadanya pada saat forum mengupas tentang korupsi, kiranya lebih dari cukup untuk kita beristighfar dan bertanya kepada diri sendiri: "Bangsa macam apa kita ini sebenarnya?". ${ }^{14}$ Penulis di sini hanya akan menambahkan data yang diberikan oleh M.S. Kaban tentang kebocoran negara dari sektor hutan dan satwa yang dicuri. "Tidak kurang dari Rp.50 triliun harta negara

${ }^{13}$ Mingguan Timpo, 5 Desember 2004, tidak kurang dari sembilan haluman telah berbicara kasus Munir ini, lihat hal. 23, 26-28, dan 30-34.

${ }^{14}$ Kolom yang cukup baik tentang ini, lihat Asro Kamal Rokan, 8 Desember 2004, "Tak Perlu Lagi Kata-Kata", Republika, hal. 12. 
yang lenyap setiap tahun dari praktik yang serba ilegal, baik kayu maupun satwa."15 Kayu dan satwa ini diambil dari berbagai pulau di Indonesia, khususnya Kalimantan dan Papua, kemudian diselundupkan ke luar negeri untuk meraup keuntungan pribadi yang fantastik, tetapi dengan mengorbankan kepentingan bangsa, negara, dản terutama rakyat kecil. Dalam penyelundupan ini, peran aparat untuk melindungi si pencuri serakah bukan rahasia lagi. Di sinilah permainan kongkalikong itu semakin menggila, seakan-akan negeri sudah tidak bertuan lagi. Akibat pencurian kayu ini, hutan-hutan sudah semakin gundul, sehingga degradasi hutan sudah mencapai 2,7 juta hektar per tahun. ${ }^{16}$

Kerusakan hutan adalah wujud belaka dari kerusakan mental orang serakah, tetapi mencelakan orang banyak di samping merusak lingkungan. Keserakahan di mana pun di muka bumi umumnya terlihat dalam dua wajah: wajah uang dan wajah kekuasaan. Yang ironis adalah bahwa hampir tidak ada penguasa yang mau belajar dari kesalahan masa lampau, yang pada umumnya disebabkan oleh laku dosa dan dusta penguasa itu sendiri. Untuk Indonesia, ada istilah "penguasaha" (penguasa yang berkolusi dengan pengusaha). Sebagai seorang senior citizen, setelah hampir 60 tahun merdeka, penulis berharap agar bangsa tidak hanya berbicara tentang siapa atau partai mana yang menang dalam pemilihan umum. Yang harus dikatakan dan diperjuangkan tanpa mengenal lelah adalah agar hati nurani dan akal sehat menjadi pemenang tunggal untuk menyelamatkan Indonesia baru yang sangat tercinta. Kemenangan hati nurani dan akal sehat dapat melumpuhkan budaya serakah yang masih belum menghilang dari tubuh bangsa ini.

Yang lumpuh adalah hati nurani

Yang lumpuh adalah akal sehat ${ }^{17}$

\section{Penutup}

Dari sini, sudah lebih dari pantas, penulis sekeluarga mengucapkan rasa haru dan terima kasih kepada Rektor, Senat Guru Besar, dan seluruh sivitas akademika Universitas Gadjah Mada atas pemberian Anugerah Hamengku Buwono IX tahun ini. Mengaitkan nama besar HB IX dengan pemberian anugerah ini tidak saja untuk mengenang jasa luar biasa dari salah seorang tokoh pendiri negara yang telah berpihak sepenuhnya kepada republik dan telah menyerahkan harta Keraton, entah berapa banyaknya, demi tegaknya bangsa dan negara pada masa revolusi. Tetapi lebih dari itu,

${ }^{15}$ Keterangan Menteri Kehutanan sewaktu saya diminta berbicara tentang perbaikan moral bangsa di Departemen Kehutanan pada 30 Nopember 2004.

${ }^{16} \mathrm{Ibid}$.

${ }^{17}$ Motto Khutbah Iftitah yang saya sampaikan dalam sidang Tanwir Muhammadiyah di Mataram (Lombok), 2-5 Desember 2004. 
HB IX yang tidak pernah bersedia menyebut jasanya, adalah kekuatan perekat yang sangat kuat bagi keutuhan bangsa. Tetapi ada satu soal yang pernah penulis sampaikan langsung kepada pewarisnya, Sri Sultan Hamengkowono X, yaitu "sekiranya HB IX mau sedikit berkata terus terang kepada Bung Karno dan Pak Harto tentang kondisi bangsa dan negara yang sebenarnya keadaan Indonesia tentu tidak akan seburuk seperti yang bangsa ini alami": Jawaban yang penulis terima adalah: "Itulah ayah saya yang pernah mengatakan kepada saya agar (saya) lebih berani." ${ }^{\prime 8} \mathrm{HB}$ IX, seorang raja tetapi terlalu menenggang perasaan orang lain sebuah kemampuan mengendalikan diri yang luar biasa, memang. Terima kasih Sri Sultan, semoga nasehat HB IX adalah nasehat untuk semua pemimpin Indonesia baru yang sedang dan yang akan muncul. Terima kasih Keraton Jogja yang telah menyediakan segala kemudahan bagi penyelenggaraan acara orasi malam ini.

\section{DAFTAR PUSTAKA}

Galtung, Johan dan Dietrich Fischer, 2002, "To End Terrorism, End State Terrorism" dalam Just Commentary, Vol: 2, No. 9.

Guralnik, David B., et al (ed.), 1970, Webster's New World Dictionary of The American Language, New York: The World Publising Company.

Habermas, Jurgen, 1987, The Philosophical Discourse of Modernity, Cambridge Mass: MIT Pres.

Metcalf, Jonathan, et. al. (ed.), 1998, Illustrated Oxford Dictionary, New York-London: Oxford University Press.

Mingguan Tempo, 5 Desember 2004.

Niezsche, F., 1976, Thus Spoke Zarathustra, terj. R.J. Hollingdale, New York: Penguin Books.

Rokan, Asro Kamal, 8 Desember 2004, "Tak Perlu Lagi Kata-Kata", Republika.

${ }^{18}$ Pembicaraan terjadi di Pagelaran Keraton pada tanggal 7 Desember 2004, pada saat Sri Sultan mengadakan jamuan malam bagi delegasi tokoh-tokoh agama dari 13 negara. 
Safranski, Rudiger, 2003, Nietzsche: A Philosophical Biography, London: Granta Books

Suryadinata, Leo, Evi Nurvidya Arifin, Aris Ananda, 2003, Indonesia 's Population: Ethnicity and Religion in a Changing Political Landscape, Singapore: Institute of Southeast Asian Studies.

Taylor, Charles, 1992, The Malaise of Modernity, Concord Ontario: Anansi.

Tibi, Bassam, 2002, The Challenge of Fundamentalism: Political Islam and The New World Disorder, Berkeley: University of California Press.

Tilaar, H.A.R., 2004, Multikulturalisme: Tatangan-tantangan Global Masa Depan dalam Transformasi Pendidikan Nasional, Jakarta: Grasindo.

Todd, Emmanuel, 2003, After The Empire: The Breakdown of The American Order, terj. C. Jon Delogu, London: Constable and Robinson.

Toynbee, A.J., 1973, Surviving The Future, New York-London: Oxford University Press.

Vattimo, Gianni, 1991, The End of Modernity, terj. John R. Snyder, Baltimore: The Johns Hopkins University Press. 